\title{
Asymmetry and Lilien's Sectoral Shifts Hypothesis: A Quantile Regression Approach
}

\author{
THEODORE PANAGIOTIDIS \\ University of Macedonia \\ and Rimini Centre for Economic Analysis * \\ GIANLUIGI PELLONI \\ Wilfrid Laurier University \\ The Johns Hopkins University, SAIS-Bologna \\ and Rimini Centre for Economic Analysis, Italy
}

\begin{abstract}
This study revisits Lilien's sectoral shifts hypothesis for the US. We employ quantile regression estimation in order to investigate the asymmetric nature of the relationship between sectoral employment and unemployment. Significant asymmetries emerge. Lilien's dispersion index is significant only for relatively high levels of unemployment and becomes insignificant for lower levels suggesting that reallocation affects unemployment only when the latter is relative high. More job reallocation is associated with higher unemployment.
\end{abstract}

Keywords: Unemployment, Employment Reallocation, Sectoral Shifts, Aggregate Shocks, Conditional Quantile Regression Model, Bootstrapping

JEL Classifications: C22, C50, E24

\section{Introduction}

The relevance of intersectoral labor reallocation as a triggering force of aggregate (un) employment fluctuations is at the core of an unsettled debate. This controversy persists because of the "observational equivalence" problem which is endemic in the sectoral shifts analysis (Lilien 1982b; Abraham and Katz, 1986). Both aggregate and allocative shocks can

\footnotetext{
* Panagiotidis: tpanag@uom.edu.gr; Pelloni: gianluigi.pelloni@gmail.com. We wish to thank Karim Abadir, Elettra Agliardi, Francesco Franceschi, Ramazan Gencay, Tony Lancaster, Angelo Melino, Angela Pelloni, Emmanuel Pikoulakis, Yongsheol Shin, Thanasis Stengos and an anonymous referee. We are also grateful to editor in charge David Andolfatto and the REA managing editor Jurek Konieczny for valuable comments and suggestions. The usual caveat applies..

(C) 2014 Theodore Panagiotidis, Gianluigi Pelloni. Licensed under the Creative Commons Attribution Noncommercial 3.0 Licence (http://creativecommons.org/licenses/by-nc/3.0/. Available at http: //rofea.org).
} 


\section{PANAGIOTIDIS, PELLONI Asymmetry and Lilien's Sectoral Shifts}

explain the observed positive correlation between unemployment and intersectoral employment dispersion signals.

Discriminating between the impact of these two sources of shocks on unemployment has become one of the unsolved challenges of empirical macroeconomics. The massive effort aimed at overcoming this identification problem has led to important analytical extensions (e.g. job creation and job destruction analysis) and a vast and growing literature (for a survey c.f. Gallipoli and Pelloni, 2013).

Originally the observational equivalence problem surfaced in linear regression approaches which can only identify the conditional mean response of unemployment to changes in the covariates. Reallocation shocks are asymmetric and non-directional by nature. The linear regression model (LRM), by restricting its informational environment to conditional mean responses, could fall short of providing useful outcomes. This study adopts a different approach which present novel features. As in Lilien (1982a), we consider a reduced form equation for unemployment but we estimate it and draw inferences within a quantile regression $(\mathrm{QR})$ framework. Such procedure allows us to look deeper into the intrinsic asymmetries of allocative shocks. A quantile regression model (QRM) allows us to quantify the impact of covariates on each unemployment quantile and so we can analyze both the conditional central location and the off-central location effects.

The structure of the paper is as follows.In section 2 we put the sectoral shifts issue into the perspective of QR. In section 3 we introduce our QRM for sectoral shifts and discuss briefly estimation and inference issues leaving details to an appendix. In section 4 we present results and finally in section 5 we draw conclusions and briefly outline possible developments.

\section{Quantile Regression and Employment Reallocation}

Lilien (1982a) claims that intersectoral shifts in demand composition could operate as the driving force of unemployment fluctuations. Idiosyncratic shocks would trigger a process of workers reallocation (from declining to expanding sectors) which could be slow enough to require prolonged unemployment spells. Periods of relatively higher aggregate unemployment would be then associated with periods of relatively higher dispersion in employment demand.

Lilien's reduced form specification can be written as:

$$
u_{t}=a_{0}+a_{1} \sigma_{t}+a_{2} D M R_{t-1}+a_{3} D M R_{t-4}+a_{4} u_{t-1}+a_{5} u_{t-4}+a_{6} \text { trend }+v_{t}
$$

where $u_{t}$ is the unemployment rate, $D M R_{t}$ is the unanticipated growth rate of $\mathrm{M} 2$ and trend is a time trend variable. The covariate $\sigma_{t}$, often called the Lilien dispersion proxy, is the weighted standard deviation of cross-sectoral employment growth rates: 
Review of Economic Analysis 6 (2014) 68-86

$$
\sigma_{t}=\left[\sum_{j}\left(N_{j, t} / N_{t}\right)\left(\Delta \ln N_{j, t}-\Delta \ln N_{t}\right)^{2}\right]^{1 / 2}
$$

where $N_{j t}$ is employment in sector $j$ at time $t$ for $j=1,2 \ldots, K, N_{t}$ is aggregate employment at time $t$, and $\left(N_{j t} / N_{t}\right)$ are weights defined by the relative size of each sector.

Lilien's empirical evidence suggests that $\sigma_{t}$ is significantly and positively correlated with $u_{t}$ over the period 1948-1980 and that much of US unemployment in the 1970's, contrary to that of the early 1960 's, can be explained by sectoral shifts. Figure 1 shows that there has been a large amount of workers reallocation in the US over the sample period, as characterized by $\sigma_{t}$, and that peaks in $\sigma_{t}$ often coincide with peaks in unemployment.

Figure 1: Unemployment rate and Lilien's $\sigma_{t}$ for the USA

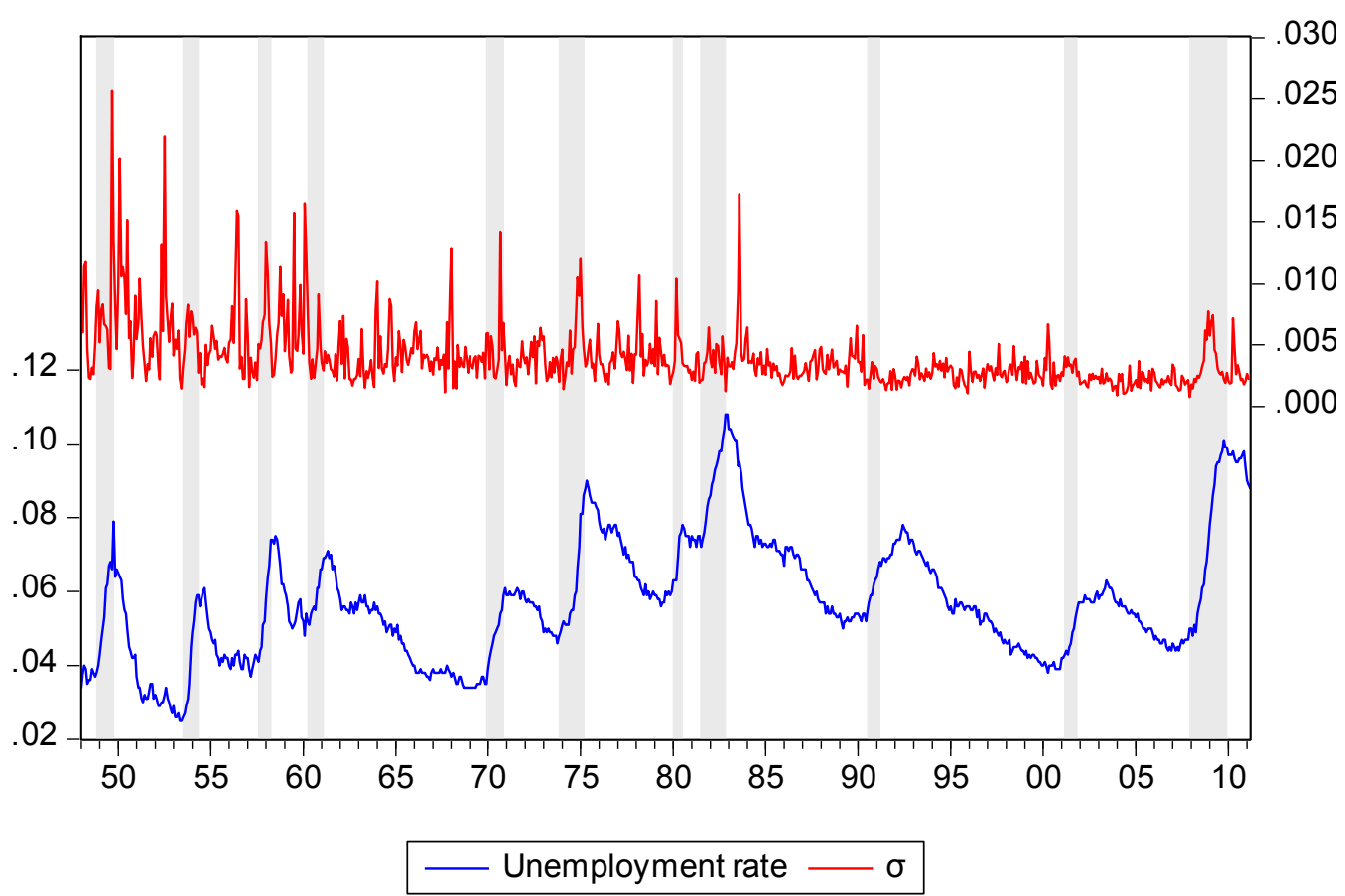

Earlier analyses of these phenomena (Lilien 1982b; Abraham and Katz 1986, 1987; Weiss 1986) showed that the positive unemployment-sectoral dispersion $(u-\sigma)$ correlation (as measured by using Lilien's proxy) could instead capture the effects of aggregate shocks if cyclical responsiveness varies across sectors. Thus two alternative theories of unemployment fluctuations could yield observationally equivalent predictions (aggregate shocks vs. sectoral shocks). Subsequent research has been moving in disparate directions and has seen a 


\section{PANAGIOTIDIS, PELLONI Asymmetry and Lilien's Sectoral Shifts}

flourishing of empirical studies but at the same time no unifying analytical framework has obtained a general consent ${ }^{1}$.

Explorations of the $(u-\sigma)$ correlation have in most cases borne out Abraham and Katz's (1986) sceptical views about sectoral shifts. ${ }^{2}$ These results, rooted in the LRM, reflect the response of the conditional mean function to a change in the covariates. They ignore the asymmetric and non-directional nature of allocative shocks. Aggregate shocks are directional (positive/negative) and through the relevant propagation mechanism, could bring about large unemployment oscillations even when they are small. In principle, these effects are reflected in each quantile of the conditional distribution of unemployment and would imply essentially a change in the central location. Reallocation shocks are disturbances unfavourable to the existing allocation of resources: a sectoral shock should bring about a reallocation process which is followed by an oscillation in aggregate unemployment. Some sectors will expand and others will contract. At the macro level, this change in demand composition is reflected in the ensuing reallocation of workers which, for given search technology, would bring about an increase in unemployment consistent with the size of the required workers reallocation. It is the magnitude of the engendered reallocations which determines the aggregate response in terms of higher unemployment. As reallocation shocks affect unemployment to the extent they are unfavourable to the current allocation of resources, small shocks generate a small unemployment increase while large shocks generate a large rise in unemployment. In analytical terms, it is the size of the shock and its asymmetric structure that count. Thus, the conditional unemployment distribution would be skewed to the left and the effects of employment reallocations on the lower quantiles will be small and insignificant.

Asymmetry together with the non-directional nature of idiosyncratic shocks have received a relatively small and restricted attention in testing the "job/labour reallocation hypothesis" (e.g. Davis and Haltiwanger, 1999; Pelloni and Polasek, 1999; Pelloni and Polasek, 2003; Panagiotidis et al 2003 and for nonlinearity Panagiotidis and Pelloni, 2007). In the context of Lilien-type approach, equations (1) and (2) above, asymmetry has played no role and most of the focus has been on the mean response and / or the volatility. ${ }^{3}$ In this paper, we take a

${ }^{1}$ See Gallipoli and Pelloni (2008) for references and details of the different approaches to the macroeconomic impact of employment reallocation.

${ }^{2}$ A notable exception is Mills et al. (1995). This article, to the best of our knowledge, uses the most updated time series methodology applied to this specific framework (i.e. a reduced form equation with a Lilien dispersion proxy).

${ }^{3}$ An exception is Byun and Hwang (2009). They emphasize that the skewness of the distribution of reallocation shocks can have a significant role in a Lilien-type model. Their empirical results show a significant effect of the skewness measure on the aggregate unemployment rate. However, they set their analysis in a LRM context and unfortunately fail to take into account recent advances in time series analysis. 
different view and suggest that modeling the conditional mean of unemployment is not an appropriate strategy as it fails to take into account the fundamental intrinsic asymmetries of allocative shocks. As a measure of central location the conditional mean would be distorting if the distribution is skewed. Furthermore, given the intrinsic skewness of the conditional unemployment distribution under the employment reallocation assumption, researchers would be interested in measuring and testing off-central location responses and changes in the shape of the conditional unemployment distribution in response to changes in the covariates. Clearly, the LRM would not be able to provide the necessary information. Preceding analyses were all based on the LRM and so all of them suffered of the shortcomings just illustrated.

In summary, in this paper we argue that two main features characterize unemployment fluctuations brought about by allocative shocks: (i) the size of the shock; and (ii) the asymmetric response of unemployment.

The first of these traits could be handled within the LRM through a polynomial representation of the dispersion proxy which would capture the non-linearity of the allocative shocks. ${ }^{4}$ However such a framework would reproduce only the shock size effect on the conditional mean. The second feature could hardly be captured within a LRM. We suggest handling the analysis of equations like (1) and (2) by using quantile regression. In fact the QRM would provide an approach capable of overcoming some of these shortcomings. It would identify variations in the conditional quantile in response to changes in the covariates and gives us the possibility to focus on different segments of the distribution. ${ }^{5}$ Our approach is not embedded within a tight theoretical framework. However, no fully developed theoretical model of sectoral shifts has been developed up to now. Our approach, similar to others in the past, is based on fundamental features of sectoral shifts. Though it may not provide a final assessment on sectoral shifts (this would have to wait for the missing theory), we maintain that it can provide important and useful clues and leads.

\section{A Benchmark QRM of Unemployment.}

We estimate linear versions of equation (1), which provide representations of how each conditional quantile of unemployment depends on Lilien's dispersion measure and a vector of aggregate covariates.

We start by providing a brief overview of the econometric methodology adopted here. Let $u_{t}$ be a random variable. The conditional quantile function (CQF) at quantile $\tau$ given a vector of regressors, $X_{i}$, can be defined as

\footnotetext{
${ }^{4}$ The second order polynomial in Davis (1986) and Loungani (1986) could fall in this line of reasoning.

${ }^{5}$ Koenker and Bassett (1978) proposed the QRM that provides estimates of the linear relationship between the covariates and a specified quantile of the dependent variable. For a detailed analysis of quantile regression see Koenker (2005). For a more concise and less technical exposition see Koenker and Hallock (2001). For a Bayesian perspective on quantile regression see Lancaster and Jun (2010).
} 
PANAGIOTIDIS, PELLONI Asymmetry and Lilien's Sectoral Shifts

$$
Q_{\tau}\left(u_{i} \mid X_{i}\right)=F_{U}^{-1}\left(\tau \mid X_{i}\right)
$$

where $F_{U}\left(\tau \mid X_{i}\right)$ is the distribution function for $u_{i}$ at $u$, conditional on $X_{i}$. When $\tau=0.5$, $Q_{\tau}\left(u_{i} \mid X_{i}\right)$ would give us the conditional median, while $\tau=0.9$ provides the upper decile of $u$ given $X_{i}$. The following minimisation problem is solved by the CQF:

$$
Q_{i}\left(u_{i} \mid X_{i}\right)=\arg \min E\left[\rho_{\tau}\left(u_{i}-q\left(X_{i}\right)\right)\right]
$$

where $\rho_{\tau}(w)=(\tau-1(w \leq 0))$ is the absolute value check function and $q\left(X_{i}\right)$ is a function of $X_{i}$. For $\tau=0.5$, we have the least absolute deviations (LAD) estimator, so that $Q_{i}\left(u_{i} \mid X_{i}\right)$ is the conditional median. The check function inserts negative and positive weights in an asymmetric way:

$$
\rho_{\tau}(w)=1(w>0) \tau|w|+(w \leq 0)(1-\tau)|w|
$$

Within the quantile regression framework, we set:

$$
\beta_{\tau} \equiv \arg \min E\left[\rho_{\tau}\left(u_{i}-X^{\prime} b\right)\right]
$$

and $\hat{\beta}_{\tau}$ is the quantile regression estimator which is obtained via solving a linear programming problem.

We wish to keep our approach as close as possible to Lilien (1982a) and Abraham and Katz (1986). Nevertheless some changes with respect to those approaches have to be introduced because of the analytical changes intervened between current methodological practices and economic insights and the ongoing state of the art prevailing at the time those seminal contributions were published.

Although the discussion on the stationarity properties of the unemployment rate is extensive, we treat $u$ as a mean reverting process. A number of unit root tests, such as the ADF, Phillips-Perron, the Zivot-Andrews (1992) with a break and the nonlinear one proposed by Kapetanios et al (2003), reject the unit root either at the $5 \%$ or at the $1 \%$ significance level (results available upon request). Abadir et al (2013) also argue that the unemployment rate is inevitably an $\mathrm{I}(0)$ series. The summary statistics of the unemployment rate is presented in Table 1. It emerges that the mean is greater than the median and there is some positive skewness. We interpret this as a signal of asymmetry. 
Review of Economic Analysis 6 (2014) 68-86

Table 1: Summary Statistics, Unemployment Rate

$\begin{array}{ll}\text { Mean } & 0.057312 \\ \text { Median } & 0.056000 \\ \text { Maximum } & 0.108000 \\ \text { Minimum } & 0.025000 \\ \text { Std. Dev. } & 0.016304 \\ \text { Skewness } & 0.666020 \\ \text { Kurtosis } & 3.297517\end{array}$

The unemployment rate is modelled as a linear function of the dispersion index $\left(\sigma_{t}\right)$, the unexpected money growth rate $\left(D M R_{t}\right)$ and lagged values of the unemployment rate. ${ }^{6}$

Our covariate, $\sigma_{t}$, is Lilien's dispersion measure that was constructed using data from the Bureau of Labor Statistics for four sectors: Construction, Finance, Manufacturing and Trade. Given that $\sigma_{t}$ could be considered as endogenous, we would need to take into account this potential endogeneity. For this reason we employ the $2 \mathrm{SQR}$ (two stage quantile regression) methodology that was developed by Kim and Muller (2004a, b). In our case we have 759 observations. Monte Carlo simulations show that the proposed estimator has good small sample properties for less than 300 observations. The first step consists of an OLS regression of $\sigma_{t}$ on a constant, two lags of $\sigma_{t}$ and two lags of the growth rate of M2. In the second step, we replace $\sigma_{t}$ with the fitted values of $\sigma_{t}\left(\hat{\sigma}_{\tau}\right)$. Kim and Muller (2004b) demonstrate that the 2SQR estimators based on an OLS first step are consistent. This approach would allow us to take into account and quantify the potential endogeneity of $\sigma_{t}$.

We proxy the monetary policy covariate with a measure of unanticipated monetary growth. We use the growth rate of M2 as a measure of monetary policy and regress its growth rate on a constant term, the federal deficit, energy inflation and a combination of autoregressive and moving average terms. The residuals of this regression quantify the unexpected growth rate of money.

The gist of our experiment is linked to the different nature of allocative and aggregate shocks. Allocative shocks being compositional and not directional induce only movements of the unemployment rate above its long run steady state value (LRSSV). For instance, if the LRSSV is $5 \%$ when an allocative shock hits the economy, unemployment will increase temporarily above its 5\% LRSSV, to converge back to it in due course when reallocations have been completed. This characteristic entails that a Lilien's proxy, if properly designed to capture sectoral shocks, would only affect significantly values of the unemployment rate above the LRSSV of unemployment. Furthermore, the compositional nature of allocative

\footnotetext{
${ }^{6}$ Koenker (2005) inserts quantile autoregression in the "twilight zone of quantile regression".
} 


\section{PANAGIOTIDIS, PELLONI Asymmetry and Lilien's Sectoral Shifts}

shocks implies that only size matters. Directional shock could affect the economy even when they are small through the magnifying effect of a propagation mechanism while allocative shock effects depend on the size of the change in demand composition. Thus we postulate that the effect of our Lilien proxy will be non-significant for the lower quantiles of a skewed conditional distribution of the unemployment rate. On the other end, aggregate shock, though not necessarily strictly symmetric, must capture variations above and below the unemployment LRSSV and would moderately affect the shape of the distribution and would tend to look like central location shifts (conditional means effects). Our experiment claims that a unit change of one of the aggregate covariates should cause every quantile to change (approximately) by the same amount because aggregate shocks would represent a centrallocation shift. Aggregate shocks might bring about scale shifts but not changes in the shape of the unemployment distribution. This property should strictly hold for nominal shocks, while the aggregate real shocks may present minor variations across quantiles because of associated distributional effects. Sectoral reallocations, operating through a one sided dimensional effect (unfavorable to the current allocation of resources) linked to the magnitude of the shock, entail a left skewed unemployment distribution. An increase of the dispersion proxy from a lower to a higher value has a greater effect on relative higher unemployment rates and would affect the shape of the unemployment distribution by increasing its left-skewness.

\section{Empirical Results}

We start our analysis with the linear benchmark model. Our experiment is carried out for the United States using monthly data for the period 1957:02-2011:03 (Data were retrieved from the Bureau of Labor Statistics). We have employed 10 quantiles to reveal the behavior of the entire conditional distribution.

Our first step is to estimate equation (1) with OLS. Given that the OLS estimates are sensitive to outliers, we also consider the robust regression of Huber (1973) (M-estimation) that is less sensitive to extreme values.

For the $\mathrm{QR}$, we have obtained estimates of the CQF via the solution of the linear programming minimization problem $\min \sum\left[\rho_{\tau}\left(u_{i}-q\left(X_{i}, \beta\right)\right]\right.$, where $\rho_{\tau}$ is the absolute value check function. A crucial estimation and inference issue concerns the estimates of the asymptotic covariance matrix. In this study, we apply bootstrapping techniques for the estimation of the covariance matrix. We use the residual bootstrap out of the various potential bootstrapping methods using 999 repetitions. The covariance matrix is constructed by resampling (with replacement) from the residuals and $X_{i}$. If $v^{*}$ is an $m$-vector of resampled residuals and $X^{*}$ is a $m \times p$ matrix of independently resampled $X$, then we can form the dependent variable using the resampled residuals, resampled data and estimated coefficients

$Y^{*}=X^{*} \hat{\beta}(\tau)+v^{*}$. Then one can construct a bootstrap estimate of $\beta(\tau)$ using $\mathrm{Y}^{*}$ and $\mathrm{X}^{*}$. These steps are repeated for $M=999$ bootstrap replications. The bootstrap covariance matrix is the 
estimate of the sample variance of the bootstrap estimates of $\beta(\tau)$ (for a detail discussion see Kocherginsky et al., 2005). In this case we have used 999 repetitions.

Table 2 presents the OLS estimation of equation 1 together with the robust estimation $(M-$ estimation) and the median response from the quantile regression $(\tau=0.5)$.

Table 2. Estimates of

$$
\begin{gathered}
u_{t}=a_{0}+a_{1} \sigma_{t}+a_{2} D M R_{t-1}+a_{3} D M R_{t-4}+a_{4} u_{t-1}+a_{5} u_{t-4}+a_{6} \text { trend }+v_{t} \text { and } \\
u_{t}=a_{0}+a_{1} \hat{\sigma}_{t}+a_{2} D M R_{t-1}+a_{3} D M R_{t-4}+a_{4} u_{t-1}+a_{5} u_{t-4}+a_{6} \text { trend }+v_{t}
\end{gathered}
$$

\begin{tabular}{|c|c|c|c|c|}
\hline \multicolumn{5}{|c|}{ Dependent Variable : Unemployment rate 1957-2011 } \\
\hline & OLS & M-estimation & QR & 2SQR \\
\hline \multirow[t]{2}{*}{ Constant } & 0.000 & 0.000 & 0.000 & -0.001 \\
\hline & 0.465 & -0.138 & -0.446 & -1.335 \\
\hline \multirow{2}{*}{$\sigma_{t}$} & $0.125 * * *$ & $0.104 * * *$ & $0.083 * *$ & \\
\hline & 3.329 & 2.864 & 2.380 & \\
\hline \multirow[t]{2}{*}{$\hat{\sigma}_{t}$} & & & & $0.165 * * *$ \\
\hline & & & & 2.589 \\
\hline \multirow[t]{2}{*}{$\mathrm{DMR}_{\mathrm{t}-1}$} & $0.010 *$ & $0.012 * *$ & $0.011 *$ & 0.009 \\
\hline & 1.757 & 2.045 & 1.952 & 1.574 \\
\hline \multirow[t]{2}{*}{$\mathrm{DMR}_{\mathrm{t}-4}$} & 0.004 & 0.003 & 0.002 & -0.003 \\
\hline & 0.739 & 0.567 & 0.300 & -0.573 \\
\hline \multirow[t]{2}{*}{ UNRATE $_{\mathrm{t}-1}$} & $1.154 * * *$ & $1.146 * * *$ & $1.134 * * *$ & $1.142 * * *$ \\
\hline & 63.624 & 65.532 & 68.393 & 72.546 \\
\hline \multirow[t]{2}{*}{ UNRATE $_{\mathrm{t}-4}$} & $-0.170 * * *$ & $-0.158 * * *$ & $-0.140 * * *$ & $-0.148 * * *$ \\
\hline & -9.302 & -8.984 & -8.375 & -9.383 \\
\hline \multirow[t]{2}{*}{ @ TREND } & $0.000^{*}$ & $0.000^{* *}$ & 0.000 & $0.000^{*}$ \\
\hline & 1.803 & 2.081 & 1.533 & 1.780 \\
\hline Adjusted R-squared & 0.987 & 0.821 & 0.885 & 0.885 \\
\hline F-statistic & 8050.395 & & & \\
\hline Prob(F-statistic) & 0.000 & & & \\
\hline Pseudo R-squared & & & 0.886 & 0.886 \\
\hline Prob(Quasi-LR stat) & & & 0.000 & 0.000 \\
\hline Prob(Rn-squared stat.) & & 0.000 & & \\
\hline Wald Test for Slope & & & 0.0001 & 0.000 \\
\hline
\end{tabular}

for the period 1957-2011

Note: $t$-statistics below each coefficient. Residual Bootstrap with 999 replications for the QR. 


\section{PANAGIOTIDIS, PELLONI Asymmetry and Lilien's Sectoral Shifts}

The dispersion measure $\sigma_{t}$ has a positive and significant effect in the unemployment rate. The latter is confirmed for the average response (OLS), the robust estimator (M-estimation) and for the median estimator $(\mathrm{QR})$. The evidence from the three alternative estimators confirms the significance and the positive effect of labour reallocation on unemployment. The lagged value of the unexpected growth rate of money is significant at the conventional levels.

Furthermore we employ the test that was purposed by Koenker and Bassett (1982) for the equality of the slope coefficients across quantiles. This would compare the slope coefficient for the median against those estimated at upper and lower quantiles. The $p$-value of the test is 0 (see Table 2) and so we conclude that the coefficients differ across quantiles. The latter result further strengthens our argument for employing quantile regressions for examining labour reallocation.

The next step would be to address the issue of the potential endogeneity of $\sigma_{t}$. We employ the 2SQR estimator and the results are also reported in Table 2. The coefficient of $\sigma_{t}$ remains positive and significant at the $1 \%$ significance level. Once engodeneity of Lilien's dispersion index is taken into account, the latter still affects unemployment. This result further confirms the previous evidence for the significance of $\sigma_{\tau}$. A large proportion of the volatility of unemployment is explained (from $88.5 \%$ to $98.7 \%$ ).

We also considered the case where the sample employed would be similar to Lilien (1982a). For this reason we re-run all our four estimators (OLS, Robust, QR and 2SQR) for the sample period 1957-1980. This would be closer to the seminal study of Lilien (1982a). The results are presented in Table 3 and only the OLS coefficient of $\sigma_{t}$ is statistically significant. The restricted sample is a possible explanation for the latter.

Once we have established the positive (average and median) impact of labour reallocation as this is measured by Lilien's $\sigma_{t}$ on unemployment, we will proceed by examining the behaviour at the other quantiles of the conditional distribution. Figure 2 present the quantile (QR) estimates together with the (bootstrap) standard errors and Figure 3 presents the 2SQR estimates with the bootstrap standard errors. The point estimates and the corresponding $p$ values are available in Tables 4 and 5

The increasing effect and significance of $\sigma_{t}$ emerges from Figures 2 and 3. The upward trend of the coefficient at the different quantiles is obvious. From Tables 4 and 5 we can get the point estimates. In Table 4 we get the QR estimates and in Table 5 the $2 \mathrm{SQR}$ ones. The coefficient of $\sigma_{t}$ increases in both cases. At relative low quantiles it is insignificant and increases up to $0.197(\mathrm{QR})$ and up to 0.465 (2SQR). The latter confirms the asymmetric nature of the relationship between the labour dispersion index and unemployment. Reallocation affects unemployment more when unemployment is relative high. In more simple words, more labour reallocation takes place when unemployment is higher as we would expect the sectoral shifts hypothesis. The money growth rates are insignificant at each quantile as it is $\mathrm{u}_{\mathrm{t}-\mathrm{4}}$. On the contrary the one period lag unemployment is highly significant 
through the entire distribution with a progressively larger impact at higher quantiles. The determinist trend variable is significant only for the lower quantiles.

Table 3. Estimates of

$$
\begin{gathered}
u_{t}=a_{0}+a_{1} \sigma_{t}+a_{2} D M R_{t-1}+a_{3} D M R_{t-4}+a_{4} u_{t-1}+a_{5} u_{t-4}+a_{6} \text { trend }+v_{t} \text { and } \\
u_{t}=a_{0}+a_{1} \hat{\sigma}_{t}+a_{2} D M R_{t-1}+a_{3} D M R_{t-4}+a_{4} u_{t-1}+a_{5} u_{t-4}+a_{6} \text { trend }+v_{t}
\end{gathered}
$$

\begin{tabular}{|c|c|c|c|c|}
\hline \multicolumn{5}{|c|}{ Dependent Variable : Unemployment rate 1957 - 1980} \\
\hline & OLS & $\begin{array}{c}\text { M- } \\
\text { estimation }\end{array}$ & QR & 2SQR \\
\hline \multirow[t]{2}{*}{ Constant } & 0.001 & 0.001 & 0.001 & 0.0004 \\
\hline & $(0.828)$ & $(1.101)$ & $(0.941)$ & $(0.387)$ \\
\hline \multirow[t]{2}{*}{$\sigma_{t}$} & $0.137 * * *$ & 0.065 & 0.064 & \\
\hline & $(2.734)$ & $(1.343)$ & $(1.320)$ & \\
\hline \multirow[t]{2}{*}{$\hat{\sigma}_{t}$} & & & & 0.036 \\
\hline & & & & $(0.180)$ \\
\hline \multirow[t]{2}{*}{$\operatorname{DMR}(\mathrm{t}-1)$} & 0.041 & 0.044 & $0.066^{* *}$ & $0.061 *$ \\
\hline & $(1.397)$ & $(1.532)$ & $(2.370)$ & $(1.750)$ \\
\hline \multirow[t]{2}{*}{$\operatorname{DMR}(\mathrm{t}-4)$} & -0.005 & -0.006 & -0.030 & -0.019 \\
\hline & $(-0.156)$ & $(-0.221)$ & $(-1.048)$ & $(-0.47)$ \\
\hline \multirow[t]{2}{*}{ UNRATE(t-1) } & $1.142 * * *$ & $1.125^{* * *}$ & $1.113 * * *$ & $1.108 * * *$ \\
\hline & $(41.476)$ & $(41.927)$ & $(42.550)$ & $(19.430)$ \\
\hline \multirow[t]{2}{*}{ UNRATE(t-4) } & $-0.17 * * *$ & $-0.151 * * *$ & $-0.13 * * *$ & $-0.125 * *$ \\
\hline & $(-6.164)$ & $(-5.631)$ & $(-5.15)$ & $(-2.380)$ \\
\hline \multirow[t]{2}{*}{ @TREND } & 0.000 & 0.000 & 0.000 & $9.01 \mathrm{E}-07$ \\
\hline & $(0.935)$ & $(0.985)$ & $(0.317)$ & $(0.362)$ \\
\hline Adjusted R-squared & 0.977 & 0.814 & 0.850 & 0.849 \\
\hline F-statistic & 1915.551 & & & \\
\hline Prob(F-statistic) & 0.000 & & & \\
\hline Pseudo R-squared & & & 0.853 & 0.852 \\
\hline Prob(Quasi-LR stat) & & & 0.000 & 0.000 \\
\hline Prob(Rn-squared stat.) & & 0.000 & & \\
\hline $\begin{array}{l}\text { Wald Test for Slope } \\
\text { Equality }\end{array}$ & & & 0.0001 & 0.756 \\
\hline
\end{tabular}

for the period 1957-1980

Note: $t$-statistics below each coefficient. Residual Bootstrap with 999 replications for the QR. 


\section{PANAGIOTIDIS, PELLONI Asymmetry and Lilien's Sectoral Shifts}

Figure 2 Quantile Estimates of

$u_{t}=a_{0}+a_{1} \sigma_{t}+a_{2} D M R_{t-1}+a_{3} D M R_{t-4}+a_{4} u_{t-1}+a_{5} u_{t-4}+a_{6}$ trend $+v_{t}$

Quantile Process Estimates
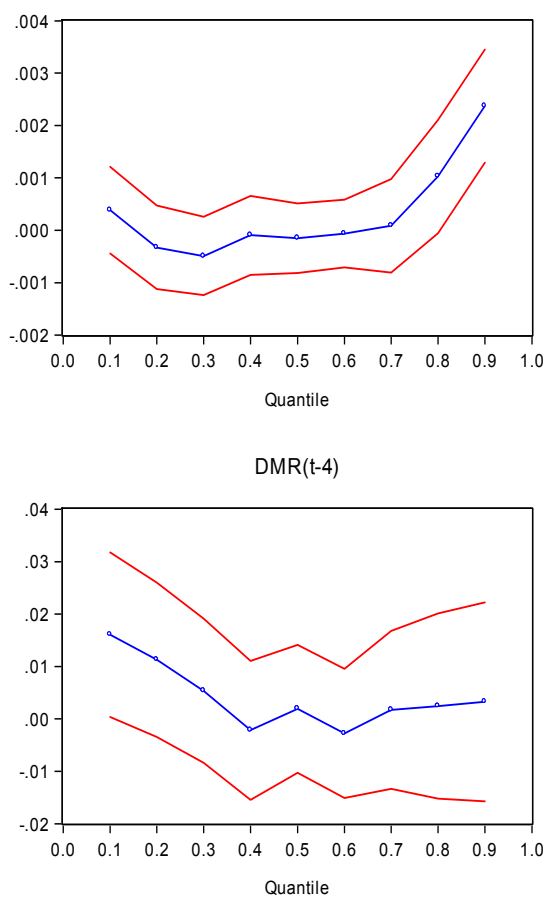

@TREND

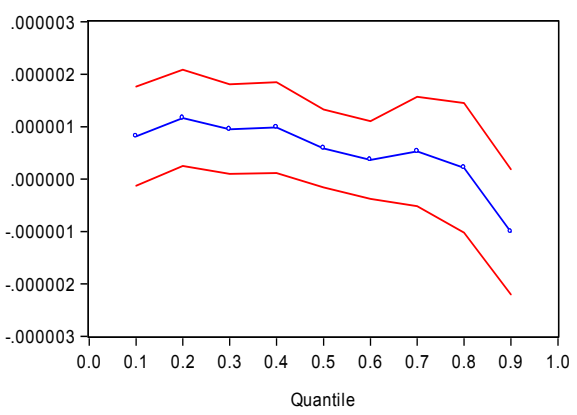

SIGMA

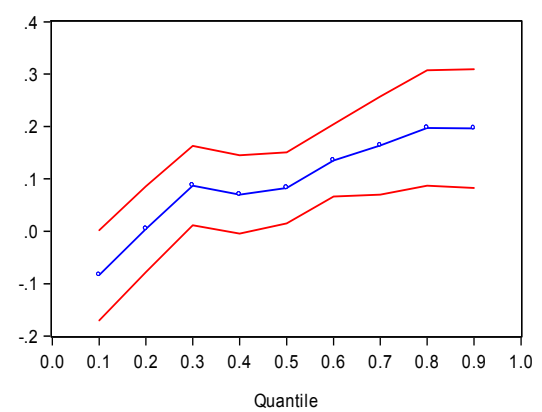

UNRATE(t-1)

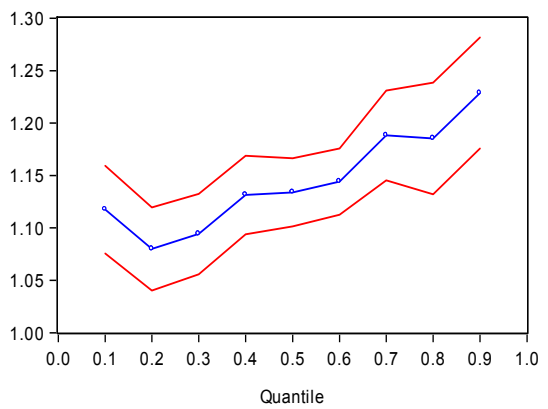

$\operatorname{DMR}(\mathrm{t}-1)$

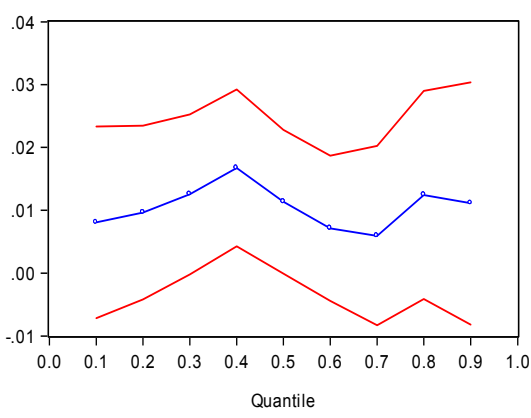

UNRATE(t-4)

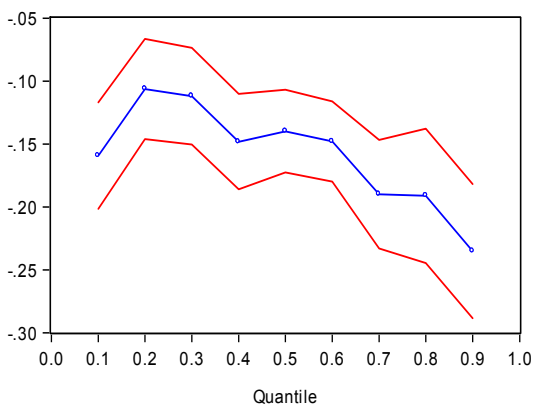

Note: Coefficient Covariance via residual bootstrap. The latter is constructed by resampling (with replacement) separately from the residuals and from the $X_{i}$. The procedure is repeated 999 times. See Kocherginsky et al (2005) for details. 
Review of Economic Analysis 6 (2014) 68-86

Figure 3 Quantile Estimates of

$u_{t}=a_{0}+a_{1} \hat{\sigma}_{t}+a_{2} D M R_{t-1}+a_{3} D M R_{t-4}+a_{4} u_{t-1}+a_{5} u_{t-4}+a_{6}$ trend $+v_{t}$

Quantile Process Estimates

C
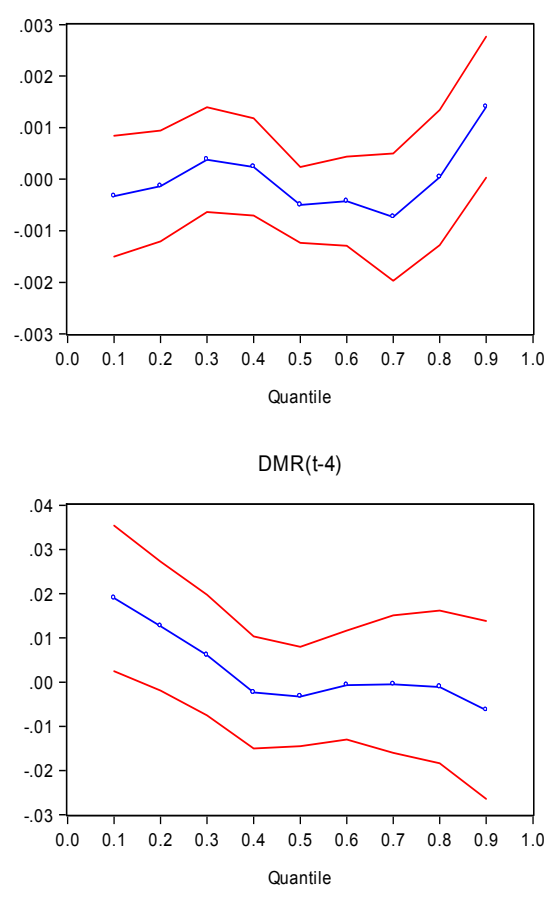

@TREND

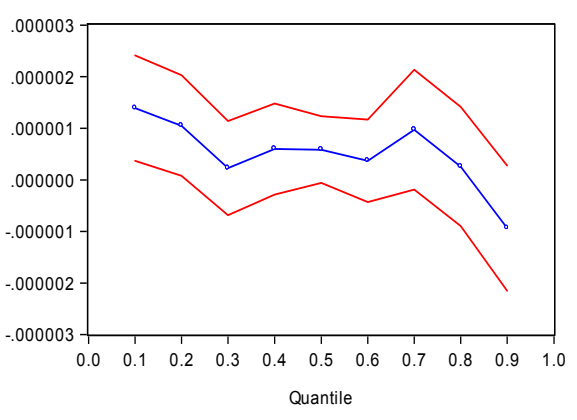

Note: See Figure 2.
SIGMA_HAT

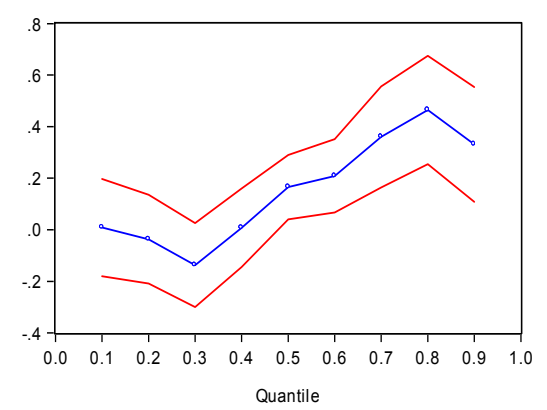

UNRATE(t-1)

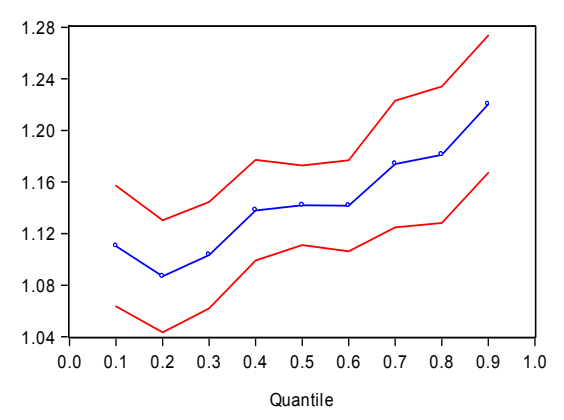

$\operatorname{DMR}(\mathrm{t}-1)$

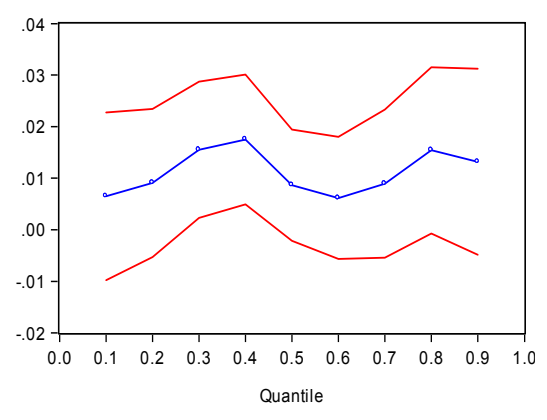

UNRATE(t-4)

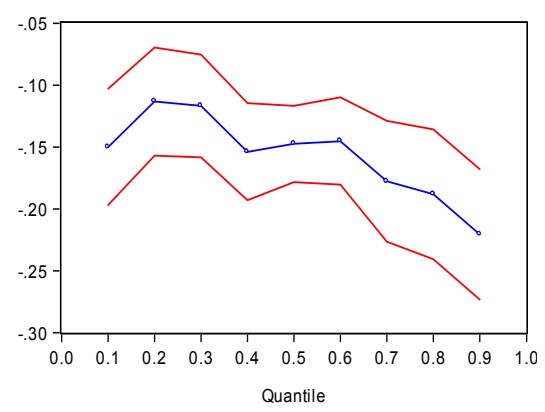


PANAGIOTIDIS, PELLONI Asymmetry and Lilien's Sectoral Shifts

Table 4: Estimates per Quantile for

$u_{t}=a_{0}+a_{1} \sigma_{t}+a_{2} D M R_{t-1}+a_{3} D M R_{t-4}+a_{4} u_{t-1}+a_{5} u_{t-4}+a_{6}$ trend $+v_{t}$

\begin{tabular}{|c|c|c|c|c|c|}
\hline & Quantile & Coefficient & Std. Error & t-Statistic & Prob. \\
\hline \multirow{9}{*}{$\mathrm{C}$} & 0.100 & 0.000 & 0.000 & 0.916 & 0.360 \\
\hline & 0.200 & 0.000 & 0.000 & -0.807 & 0.420 \\
\hline & 0.300 & 0.000 & 0.000 & -1.290 & 0.197 \\
\hline & 0.400 & 0.000 & 0.000 & -0.252 & 0.801 \\
\hline & 0.500 & 0.000 & 0.000 & -0.445 & 0.656 \\
\hline & 0.600 & 0.000 & 0.000 & -0.191 & 0.849 \\
\hline & 0.700 & 0.000 & 0.000 & 0.191 & 0.849 \\
\hline & 0.800 & 0.001 & 0.001 & 1.860 & 0.063 \\
\hline & 0.900 & 0.002 & 0.001 & 4.301 & 0.000 \\
\hline \multirow{9}{*}{ SIGMA } & 0.100 & "-0.084 & 0.044 & -1.919 & 0.055 \\
\hline & 0.200 & 0.004 & 0.042 & 0.092 & 0.926 \\
\hline & 0.300 & 0.087 & 0.039 & 2.244 & 0.025 \\
\hline & 0.400 & 0.070 & 0.038 & 1.839 & 0.066 \\
\hline & 0.500 & 0.083 & 0.035 & 2.378 & 0.018 \\
\hline & 0.600 & 0.135 & 0.035 & 3.832 & 0.000 \\
\hline & 0.700 & 0.164 & 0.048 & 3.417 & 0.001 \\
\hline & 0.800 & 0.197 & 0.056 & 3.511 & 0.001 \\
\hline & 0.900 & 0.196 & 0.058 & 3.397 & 0.001 \\
\hline \multirow{9}{*}{$\operatorname{DMR}(-1)$} & 0.100 & 0.008 & 0.008 & 1.036 & 0.301 \\
\hline & 0.200 & 0.010 & 0.007 & 1.365 & 0.173 \\
\hline & 0.300 & 0.013 & 0.006 & 1.932 & 0.054 \\
\hline & 0.400 & 0.017 & 0.006 & 2.629 & 0.009 \\
\hline & 0.500 & 0.011 & 0.006 & 1.951 & 0.052 \\
\hline & 0.600 & 0.007 & 0.006 & 1.206 & 0.228 \\
\hline & 0.700 & 0.006 & 0.007 & 0.817 & 0.414 \\
\hline & 0.800 & 0.012 & 0.008 & 1.472 & 0.141 \\
\hline & 0.900 & 0.011 & 0.010 & 1.131 & 0.259 \\
\hline
\end{tabular}


Review of Economic Analysis 6 (2014) 68-86

Table 4 continued

\begin{tabular}{|c|c|c|c|c|c|}
\hline & Quantile & Coefficient & Std. Error & t-Statistic & Prob. \\
\hline \multirow{9}{*}{$\operatorname{DMR}(-4)$} & $\begin{array}{l}0.100 \\
\end{array}$ & 0.016 & 0.008 & 1.998 & 0.046 \\
\hline & 0.200 & 0.011 & 0.007 & 1.500 & 0.134 \\
\hline & 0.300 & 0.005 & 0.007 & 0.761 & 0.447 \\
\hline & 0.400 & -0.002 & 0.007 & -0.325 & 0.745 \\
\hline & 0.500 & 0.002 & 0.006 & 0.300 & 0.764 \\
\hline & 0.600 & -0.003 & 0.006 & -0.447 & 0.655 \\
\hline & 0.700 & 0.002 & 0.008 & 0.219 & 0.827 \\
\hline & 0.800 & 0.002 & 0.009 & 0.269 & 0.788 \\
\hline & 0.900 & 0.003 & 0.010 & 0.333 & 0.739 \\
\hline \multirow{9}{*}{ UNRATE(-1) } & 0.100 & 1.117 & 0.021 & 52.388 & 0.000 \\
\hline & 0.200 & 1.080 & 0.020 & 53.223 & 0.000 \\
\hline & 0.300 & 1.094 & 0.020 & 55.939 & 0.000 \\
\hline & 0.400 & 1.131 & 0.019 & 58.938 & 0.000 \\
\hline & 0.500 & 1.134 & 0.017 & 68.358 & 0.000 \\
\hline & 0.600 & 1.144 & 0.016 & 70.971 & 0.000 \\
\hline & 0.700 & 1.188 & 0.022 & 54.383 & 0.000 \\
\hline & 0.800 & 1.185 & 0.027 & 43.652 & 0.000 \\
\hline & 0.900 & 1.229 & 0.027 & 45.372 & 0.000 \\
\hline \multirow{9}{*}{ UNRATE(-4) } & 0.100 & -0.159 & 0.022 & -7.393 & 0.000 \\
\hline & 0.200 & -0.107 & 0.020 & -5.233 & 0.000 \\
\hline & 0.300 & -0.112 & 0.020 & -5.700 & 0.000 \\
\hline & 0.400 & -0.148 & 0.019 & -7.640 & 0.000 \\
\hline & 0.500 & -0.140 & 0.017 & -8.371 & 0.000 \\
\hline & 0.600 & -0.148 & 0.016 & -9.109 & 0.000 \\
\hline & 0.700 & -0.190 & 0.022 & -8.620 & 0.000 \\
\hline & 0.800 & -0.191 & 0.027 & -7.007 & 0.000 \\
\hline & 0.900 & -0.235 & 0.027 & -8.651 & 0.000 \\
\hline \multirow{9}{*}{ @TREND } & $\begin{array}{l}0.100 \\
\end{array}$ & $\begin{array}{l}0.000 \\
\end{array}$ & $\begin{array}{l}0.000 \\
\end{array}$ & 1.680 & 0.093 \\
\hline & 0.200 & 0.000 & 0.000 & 2.479 & 0.013 \\
\hline & 0.300 & 0.000 & 0.000 & 2.178 & 0.030 \\
\hline & 0.400 & 0.000 & 0.000 & 2.203 & 0.028 \\
\hline & 0.500 & 0.000 & 0.000 & 1.532 & 0.126 \\
\hline & 0.600 & 0.000 & 0.000 & 0.949 & 0.343 \\
\hline & 0.700 & 0.000 & 0.000 & 0.987 & 0.324 \\
\hline & 0.800 & 0.000 & 0.000 & 0.334 & 0.739 \\
\hline & 0.900 & 0.000 & 0.000 & -1.660 & 0.097 \\
\hline
\end{tabular}


PANAGIOTIDIS, PELLONI Asymmetry and Lilien's Sectoral Shifts

Table 5: Estimates per Quantile for

$$
u_{t}=a_{0}+a_{1} \hat{\sigma}_{t}+a_{2} D M R_{t-1}+a_{3} D M R_{t-4}+a_{4} u_{t-1}+a_{5} u_{t-4}+a_{6} \text { trend }+v_{t}
$$

\begin{tabular}{|c|c|c|c|c|c|}
\hline & Quantile & Coefficient & Std. Error & $\mathrm{t}$-Statistic & Prob. \\
\hline \multirow[t]{9}{*}{$\overline{\mathrm{C}}$} & 0.100 & 0.000 & 0.000 & 0.916 & 0.360 \\
\hline & 0.200 & 0.000 & 0.000 & -0.807 & 0.420 \\
\hline & 0.300 & 0.000 & 0.000 & -1.290 & 0.197 \\
\hline & 0.400 & 0.000 & 0.000 & -0.252 & 0.801 \\
\hline & 0.500 & 0.000 & 0.000 & -0.445 & 0.656 \\
\hline & 0.600 & 0.000 & 0.000 & -0.191 & 0.849 \\
\hline & 0.700 & 0.000 & 0.000 & 0.191 & 0.849 \\
\hline & 0.800 & 0.001 & 0.001 & 1.860 & 0.063 \\
\hline & 0.900 & 0.002 & 0.001 & 4.301 & 0.000 \\
\hline \multirow[t]{9}{*}{ SIGMA } & "0.100 & "-0.084 & "0.044 & "-1.919 & 0.055 \\
\hline & 0.200 & 0.004 & 0.042 & 0.092 & 0.926 \\
\hline & 0.300 & 0.087 & 0.039 & 2.244 & 0.025 \\
\hline & 0.400 & 0.070 & 0.038 & 1.839 & 0.066 \\
\hline & 0.500 & 0.083 & 0.035 & 2.378 & 0.018 \\
\hline & 0.600 & 0.135 & 0.035 & 3.832 & 0.000 \\
\hline & 0.700 & 0.164 & 0.048 & 3.417 & 0.001 \\
\hline & 0.800 & 0.197 & 0.056 & 3.511 & 0.001 \\
\hline & 0.900 & 0.196 & 0.058 & 3.397 & 0.001 \\
\hline \multirow[t]{9}{*}{ DMR(-1) } & 0.100 & 0.008 & 0.008 & 1.036 & 0.301 \\
\hline & 0.200 & 0.010 & 0.007 & 1.365 & 0.173 \\
\hline & 0.300 & 0.013 & 0.006 & 1.932 & 0.054 \\
\hline & 0.400 & 0.017 & 0.006 & 2.629 & 0.009 \\
\hline & 0.500 & 0.011 & 0.006 & 1.951 & 0.052 \\
\hline & 0.600 & 0.007 & 0.006 & 1.206 & 0.228 \\
\hline & 0.700 & 0.006 & 0.007 & 0.817 & 0.414 \\
\hline & 0.800 & 0.012 & 0.008 & 1.472 & 0.141 \\
\hline & 0.900 & 0.011 & 0.010 & 1.131 & 0.259 \\
\hline
\end{tabular}


Review of Economic Analysis 6 (2014) 68-86

Table 5 continued

\begin{tabular}{|c|c|c|c|c|c|}
\hline & Quantile & Coefficient & Std. Error & t-Statistic & Prob. \\
\hline \multirow[t]{9}{*}{ DMR(-4) } & 0.100 & 0.016 & 0.008 & 1.998 & 0.046 \\
\hline & 0.200 & 0.011 & 0.007 & 1.500 & 0.134 \\
\hline & 0.300 & 0.005 & 0.007 & 0.761 & 0.447 \\
\hline & 0.400 & -0.002 & 0.007 & -0.325 & 0.745 \\
\hline & 0.500 & 0.002 & 0.006 & 0.300 & 0.764 \\
\hline & 0.600 & -0.003 & 0.006 & -0.447 & 0.655 \\
\hline & 0.700 & 0.002 & 0.008 & 0.219 & 0.827 \\
\hline & 0.800 & 0.002 & 0.009 & 0.269 & 0.788 \\
\hline & 0.900 & 0.003 & 0.010 & 0.333 & 0.739 \\
\hline \multirow[t]{9}{*}{ UNRATE(-1) } & 0.100 & 1.117 & 0.021 & 52.388 & 0.000 \\
\hline & 0.200 & 1.080 & 0.020 & 53.223 & 0.000 \\
\hline & 0.300 & 1.094 & 0.020 & 55.939 & 0.000 \\
\hline & 0.400 & 1.131 & 0.019 & 58.938 & 0.000 \\
\hline & 0.500 & 1.134 & 0.017 & 68.358 & 0.000 \\
\hline & 0.600 & 1.144 & 0.016 & 70.971 & 0.000 \\
\hline & 0.700 & 1.188 & 0.022 & 54.383 & 0.000 \\
\hline & 0.800 & 1.185 & 0.027 & 43.652 & 0.000 \\
\hline & 0.900 & 1.229 & 0.027 & 45.372 & 0.000 \\
\hline \multirow[t]{9}{*}{ UNRATE(-4) } & 0.100 & -0.159 & 0.022 & -7.393 & 0.000 \\
\hline & 0.200 & -0.107 & 0.020 & -5.233 & 0.000 \\
\hline & 0.300 & -0.112 & 0.020 & -5.700 & 0.000 \\
\hline & 0.400 & -0.148 & 0.019 & -7.640 & 0.000 \\
\hline & 0.500 & -0.140 & 0.017 & -8.371 & 0.000 \\
\hline & 0.600 & -0.148 & 0.016 & -9.109 & 0.000 \\
\hline & 0.700 & -0.190 & 0.022 & -8.620 & 0.000 \\
\hline & 0.800 & -0.191 & 0.027 & -7.007 & 0.000 \\
\hline & 0.900 & -0.235 & 0.027 & -8.651 & 0.000 \\
\hline \multirow[t]{9}{*}{ @@TREND } & 0.100 & 0.000 & 0.000 & 1.680 & 0.093 \\
\hline & 0.200 & 0.000 & 0.000 & 2.479 & 0.013 \\
\hline & 0.300 & 0.000 & 0.000 & 2.178 & 0.030 \\
\hline & 0.400 & 0.000 & 0.000 & 2.203 & 0.028 \\
\hline & 0.500 & 0.000 & 0.000 & 1.532 & 0.126 \\
\hline & 0.600 & 0.000 & 0.000 & 0.949 & 0.343 \\
\hline & 0.700 & 0.000 & 0.000 & 0.987 & 0.324 \\
\hline & 0.800 & 0.000 & 0.000 & 0.334 & 0.739 \\
\hline & 0.900 & 0.000 & 0.000 & -1.660 & 0.097 \\
\hline
\end{tabular}


PANAGIOTIDIS, PELLONI Asymmetry and Lilien's Sectoral Shifts

\section{Conclusions}

We revisit the sectoral shifts hypothesis 30 years after the seminal paper of Lilien (1982a). Employing US data from the period 1948 to 2011, we examine the case of asymmetry within a quantile regression framework. Lilien's dispersion proxy was used as a measure of turbulence in the labour market. We considered OLS, M-estimation that is robust to outliers and quantile regression that relaxes the assumption of symmetry. Additionally, we did take into account the potential endogeneity of the dispersion proxy within a two stage quantile regression framework. Significant asymmetries consistent with the sectoral shifts hypothesis are revealed. Labour reallocation is found to be significant only when unemployment takes relative high values (relative to its median) whereas becomes insignificant when unemployment is low. That is, as predicted by the sectoral shifts hypothesis, the effects of labour reallocation are significant at higher level of unemployment.

\section{References}

Abadir K., M., Caggiano, G., and Talmain G. (2013) Nelson-Plosser revisited: The ACF approach, Journal of Econometrics, 175(1), 22-34.

Abraham, K. G., and L. F. Katz (1986) Cyclical Unemployment: Sectoral Shifts orAggregate Disturbances? Journal of Political Economy, 94(3), 507-522.

Abraham, K. G., and L. F. Katz (1987) Cyclical Unemployment: Sectoral Shifts or Aggregate Disturbances? NBER Working Papers 1410, National Bureau of Economic Research.

Byun Y. and Hwang H-S., (2009) Measurements of sectoral shifts: dispersion and skewness, mimeo.

Davis, S.J., (1988) Allocative Disturbances and Temporal Asymmetry In Unemployment Rate Fluctuations,Papers88-57, Chicago, Graduate School of Business.

Davis, S. J., and J. Haltiwanger (1999) On the Driving Forces behind Cyclical Movements in Employment and Job Reallocation, American Economic Review, 89(5), 1234-1258.

Gallipoli G. and Pelloni G. (2013) Aggregate Shocks vs Reallocation Shocks: An appraisal of the applied literature, forthcoming Review of Economic Analysis.

Huber, P. J. (1973) Robust Regression: Asymptotics, Conjectures and Monte Carlo, The Annals of Statistics, 1(5), 799-821.

Kapetanios, G., Shin, Y., and Snell, A. (2003) Testing for a Unit Root against Nonlinear STAR models, Journal of Econometrics, 112(2), 359-379.

Keane, M. P. (1991) Sectoral Shift Theories of Unemployment: Evidence from Panel Data, Institute for Empirical Macroeconomics, Federal Reserve Bank of Minneapolis, Research Department, Discussion Paper 28.

Kim, T.-H., Muller, C., (2004a) Two-stage quantile regression when the first stage is based on quantile regression. Econometrics Journal, 7, 218-231. 
Kim, T.-H., Muller, C., (2004b) Two-stage quantile regression. Working Paper

Kocherginsky, M., He, X. and Mu, Y. (2005) Practical Confidence Intervals for Regression Quantiles, Journal of Computational and Graphical Statistics, 14(1), 41-55.

Koenker, R., (2005) Quantile Regression, Cambridge University Press

Koenker, R., and K.F. Hallock, (2001) Quantile Regression, Journal of Economic Perspectives, 15(4), 143-156.

Koenker, R. and Bassett, G (1978) Regression Quantiles, Econometrica, 46, 33-50,

Koenker, R and Machado, J.A. F. (1999) GMM inference when the number of moment conditions is large, Journal of Econometrics, 93(2), 327-344.

Lancaster T. and Jun S.J. (2010) Bayesian quantile regression methods, Journal of Applied Econometrics, 25(2), 287-307.

Lilien D. M. (1982a) Sectoral shifts and cyclical unemployment, Journal of Political Economy,90(4), 777-793.

Lilien D. M. (1982b) A sectoral model of business cycle, MRG WP no. 8231, University of Southern California.

Mills T.C., Pelloni G. and Zervoyianni A. (1995) Fluctuations in the US: Further Tests of the Sectoral Shifts Hypothesis, The Review of Economics and Statistics, 77 (2), 294-304.

Panagiotidis T. and Pelloni G., (2007) Nonlinearity in the Canadian and U.S. Labor Markets: Univariate and Multivariate Evidence From A Battery of Tests, Macroeconomic Dynamics, 11(05), 613-637.

Panagiotidis T., Pelloni G. and Polasek, W. (2003), Macroeconomic effects of reallocation shocks: A generalised Impulse Response Function analysis for three European Countries, Journal of Economic Integration, 18, 794-816.

Pelloni G. and Polasek W. (1999) Intersectoral Labour reallocation and Employment Volatility: A Bayesian Analysis using a VAR-GARCH-M model, Discussion Paper 99/4, Department of Economics, University of York.

Pelloni G. and Polasek W. (2003) Macroeconomic effects of sectoral shocks in Germany, the U.K., U.S.: aVAR-GARCH-M approach, Computational Economics, 21 (1\&2), 65-85.

Phillips P.C.B and Perron P. (1988) Testing for a Unit Root in Time Series Regression, Biometrika, 75 (2), 335-346

Wallis K.F. (1987), Time series analysis of bounded economic variables, Journal of Time Series Analysis, 8(1), 115-123.

Weiss L. (1986), Asymmetric Adjustment Costs and Sectoral Shifts, in "Equilibrium Analysis: Essays in Honor of Kenneth J. Arrow”, ed. by R. S. W. P. Heller, and D. Starret, CUP, Cambridge.

Zivot E. and Andrews D. W. K. (1992), Further Evidence on the Great Crash, the Oil-Price Shock, and the Unit-Root Hypothesis, Journal of Business \& Economic Statistics, 10 (3), 251-270. 